\title{
Tempo do evento, poética da história: maio de 1968 segundo Michel de Certeau e Cornelius Castoriadis
}

\author{
Time of the event, poetics of history: May 1968 according to \\ Michel de Certeau and Cornelius Castoriadis
}

\section{RESUMO:}

Este artigo analisa e estabelece comparações entre as interpretações de Michel de Certeau e Cornelius Castoriadis sobre as manifestações de maio de 1968. São privilegiados os escritos produzidos por ambos os autores na própria conjuntura do evento, não obstante relações com textos posteriores também sejam realizadas. Por meio da análise desses materiais distintos, sugere-se a relevância dos acontecimentos de 1968 para a formulação de algumas ideias-chave dos dois autores, sobretudo no que diz respeito ao significado conferido ao evento como o surgimento do novo, do inesperado, do impensável. Essa valorização da radical novidade das ocorrências de maio se relacionava com pressupostos ontológicos sobre a temporalidade da história como experiência vivida, mas também incidia sobre os fundamentos epistemológicos da história como forma de escrita. Suas análises, portanto, permitem explorar importantes implicações teóricas, políticas e até mesmo poéticas do significado conferido ao evento pela historiografia.

\section{PALAVRAS CHAVE:}

Escrita da História; Acontecimento; Tempo histórico

\author{
Douglas Attila Marcelino \\ http://orcid.org/0000-0002-0389-4754 (D) \\ org/0000-0002-0389-4754 (iD
}

\section{ABSTRACT:}

This article analyzes and establishes comparisons between Michel de Certeau's and Cornelius Castoriadis' interpretations of the demonstrations of May 1968. The writings produced by both authors at that time are privileged; however, relations with later texts are also made. In the analysis of the distinct materials, the relevance of what happened in 1968 for the formulation of some key ideas of both authors is suggested, above all in relation to the meaning given to the event as the emergence of the new, the unexpected, the unthinkable. This valorization of the radical novelty of what happened in May 1968 is related to ontological assumptions about the temporality of history as lived experience, but also impacting on the epistemological foundations of history as a form of writing. Their analyses, therefore, allow the exploration of important theoretical, political and even poetic implications of the meaning given to the event in historiography.

\section{KEYWORDS:}

Writing of History; Event; Historical Time 
Era uma verdadeira competição de quem difamaria mais Maio de 68: a aversão a Maio de 68 era a única coisa que eles propunham.

Gilles Deleuze ${ }^{1}$

São muitos os espectros de maio de 1968. Materializados nas mais diversas formas de produção cultural, que se acumulam e solidificam camadas de memória, estimulam polêmicas, controvérsias, eles também configuram uma espécie de poética do evento, com seu potencial sedutor ao analista que, ao iniciar sua interpretação, sofre um apelo subjetivo ao uso dos famosos e inventivos slogans de cartazes fixados nos muros parisienses. 0 potencial metafórico e a contundência das frases, sua capacidade de gerar imagens, somando-se assim com toda expressividade de conhecida iconografia, as inversões de teor festivo que, com sua ironia, solidificam teses em favor da contraposição entre riso e autoritarismo são alguns dos elementos que fornecem uma ampla paleta de cores por meio das quais se poderia pintar, num esforço impressionista ou romântico (a depender da escolha do gênero), os contornos daquela experiência. A simples força de tal sedução muito indica da presença dos espectros do acontecimento: na verdade, o avanço sobre os rastros do passado em favor de sua figuração como "evento" já traz consigo a assimilação de convenções, transformadas em pressupostos, nem sempre problematizados.

Os dilemas da figuração desses rastros, por outro lado, nem sempre escapam àqueles que são colocados na posição de atores, testemunhas e, também, analistas, por serem considerados vozes especializadas no momento de ocorrência da experiência. Experiência, vale ressaltar, que não significa sincronia com ações ou acontecimentos identificados como um "evento", mas sim uma atmosfera, demarcada pela partilha de afetos e percepções advindas da intensidade de sua presença na memória. Tal presença, como é natural, tende a ser mais consistente tão próxima quanto esteja do ocorrido, ainda que não seja incomum uma rememoração, com forte carga dramática e afetiva, de acontecimentos mais distantes no tempo.

1 - Afirmação de Gilles Deleuze realizada em 1977, a propósito dos chamados "novos filósofos" (DELEUZE apud DOSSE 2010, p. 166). 
Neste artigo, analisam-se as interpretações sobre maio de 1968 realizadas por dois intelectuais que participaram e examinaram aquela experiência: Michel de Certeau e Cornelius Castoriadis. Ao final, além de importantes diferenças, talvez - leitor possa encontrar surpreendentes semelhanças, ao menos se considerarmos tratar-se de dois autores com visões largamente discordantes, por exemplo, quanto ao papel que conferiam ao religioso em seu pensamento.

Focaremos nossa abordagem nos escritos elaborados já em 1968 por ambos os autores, ainda que existam algumas diferenças entre textos que visavam à ação direta dos manifestantes e outros, realizados com o objetivo específico de interferir no debate público sobre o ocorrido. Essas diferenças, que serão explicitadas nos tópicos seguintes, não dificultam o estabelecimento do aspecto central de análise: seria possível encontrar, nessas avaliações conjunturais, pressupostos ontológicos e, no caso de Michel de Certeau, poéticos que, desenvolvidos em elaborações intelectuais posteriores, remetem para o caráter do "evento", o "ser" do passado, ou ainda para a específica temporalidade de uma experiência que seria verdadeiramente histórica? Ambos os autores parecem ter tomado maio de 1968 como um desafio às formas existentes do pensamento, uma espécie de provação para os determinismos, ontológicos e epistemológicos, que tendem a se estabelecer desconsiderando a irredutibilidade das formações e das experiências sócio-históricas. A densidade de suas reflexões permite, ao menos, questionar se aquela não foi uma experiência fundamental ao desenvolvimento de ideias-força sabidamente centrais em escritos posteriores acerca do que caracteriza o "evento" (espaço para o surgimento do novo, com sua específica temporalidade), o "homem" (sua capacidade de "criação", de transformação pela "transgressão", de "invenção"), a "história" (como escrita, "historiografia"; como experiência, nas figuras da "criação", "alteridade", "diferença"). ${ }^{2}$
2 - Destaque-se, portanto, a especificidade deste estudo em relação àqueles centrados na análise de maio de 1968 ou no confronto entre dados de pesquisas sobre o evento e os escritos de ambos os autores (ver, por exemplo, ZANCARINI-FOURNEL 2002; PREMAT 2009a). 


\section{A "revoluçāo simbólica", segundo Michel de} Certeau

Michel de Certeau teve um papel ativo durante os eventos de maio e junho de 1968 e estabeleceu uma reflexão importante sobre as manifestações então ocorridas, que foram depois reunidas, com pequenas modificações, no livro La prise de parole, publicado em outubro de 1968 (GIARD 1994, p. 22-23). Os supostos motivos e os pormenores de sua intensa atuação já foram analisados por reconhecidos estudiosos, que forneceram elementos relevantes à compreensão da situação particular em que se encontrava quando eclodiram as manifestações - seja pela vinculação com suas temáticas de pesquisa; pelo lugar que indivíduos da sua geração ocupavam diante das demandas e expectativas dos mais jovens; ou, ainda, pelas particularidades trágicas de sua vida pessoal, marcada, entre outros, por um conjunto de lutos familiares (GIARD 1994).

Os textos de La prise de parole foram, originalmente, publicados entre junho e outubro de 1968 na revista Études, ${ }^{3}$ periódico mensal da Companhia de Jesus. ${ }^{4}$ Apenas um artigo veio a público, na mesma revista, em maio de $1969 .{ }^{5}$ Nossa análise tomará esses textos como objeto central, por terem sido elaborados na conjuntura do evento, mas não deixaremos de considerar possíveis diálogos com outras produções anteriores ou da mesma época.

Michel de Certeau direcionou para o plano do simbólico sua análise dos acontecimentos de maio-junho de 1968, visando interpretar os significados das ações que caracterizaram aquela experiência e ressaltando toda a teatralização e o sentido ritual daquelas práticas. ${ }^{6}$ Seja pela nova topografia idealizada, com desfiles que recompunham a clássica geografia das greves e outros movimentos contestatórios; seja pelo tom festivo, que conferia novas roupagens àqueles dias de crise e de violência; seja ainda pelo riso, transformado em arma contra a intolerância governamental, pelos novos usos conferidos às barricadas, pela valorização da criação poética e da imaginação, o que 
se verificava, enfim, era a inauguração de um novo estilo de experiência, pelo qual os gestos obtinham mais relevância do que programas de ação preestabelecidos. "Revolução simbólica", ela mais significava do que efetuava, tornando necessária uma interpretação histórica e antropológica da inversão de sentidos produzida por meio da retomada de signos já carregados de significados socialmente estabelecidos.

"Tomada da palavra", essa seria a expressão que melhor sintetizava todo o vocabulário simbólico e a batalha ritualística então verificada. As noções de "ação simbólica" e de "experiência" pareciam categorias centrais de análise. Elas permitiam enfatizar o papel fundamental do símbolo, mas também sua relação com as práticas, já que o aspecto mais significativo dos eventos de maio-junho era a inversão dos lugares sociais então encenada, com suas implicações no que diz respeito ao uso da palavra. "A palavra, do início ao fim, jogou um papel decisivo, desde a de Daniel Cohn-Bendit até aquela do general de Gaulle", destacava (CERTEAU 1994e, p. 32-33). ${ }^{7}$ As reivindicações de autonomia e de autogestão, de uma experiência direta da democracia, a ocupação estudantil das universidades e a tomada do lugar dos professores, a valorização de uma linguagem comum que superasse a divisão entre trabalho intelectual e manual, entre outros, colocavam em questão as possibilidades de uso da palavra numa sociedade hierarquizada, racionalista e burocrática.

As contestações visavam, de fato, o sistema como um todo, tornando-se sintoma de um problema geral, já que as características mencionadas permeavam e estruturavam as formas de organização das instituições em sua diversidade (as universidades, mas também os partidos, os sindicatos, a Igreja etc.). $O$ que estava em jogo era todo o sistema de representação, já que Michel de Certeau partilhava de uma noção ampla de representação: à crise da representação política correspondia um descrédito do saber, pois haveria uma homologia na forma de funcionamento desses dois planos. Características tomadas como fundamentais da 
representação política, como sua expressão por meio de uma totalidade ilusória, sua suscetibilidade ao controle e sua função operatória conformariam também o saber, tornando a crise um fenômeno de teor globalizante, já que era a coerência interna do sistema de representação como um todo que havia sido posta à prova. Fundamental, mas mantida por um frágil equilíbrio, essa coerência havia sido deslocada pelos eventos de maio, evidenciando a importância da linguagem como elemento central da crise: "a doença (se é que existe uma!) que evidencia uma tão profunda evolução consiste em tomar a linguagem a sério, ou a recusar que ela se torne um jogo, 0 jogo de ninguém" (CERTEAU 1994b, p. 62). ${ }^{8}$

Outra categoria central, que colocava igualmente em primeiro plano essa dimensão linguística dos eventos de maiojunho, era a de "transgressão". Sem dúvida, ela remetia a análise de Michel de Certeau para todo um amplo conjunto de pesquisas anteriores, voltadas para os desvios e deslocamentos realizados por aqueles que não detêm uma linguagem própria, tal como se pode verificar em seus estudos sobre os séculos XVI e XVII (os místicos, as possuídas, os indígenas, por exemplo). Também nas manifestações de maio-junho, o que estava em questão era "a criação de um lugar no qual a fala que rejeita, que recria, é possível" (CERTEAU 1994e, p. 37). A "tomada da palavra" não representava uma tomada do poder, de fato, mas uma recomposição do campo dos possíveis, um alargamento da palavra àqueles cuja expressão era tacitamente admitida como impossível. Por meio dos deslocamentos e desvios operados no vocabulário existente, desestabilizavam-se os limites entre o dito e o não dito, reconfigurando as fronteiras entre o permitido e o interditado e abrindo, assim, espaço para aquilo que somente poderia se manifestar como recusa, como falta, como "brecha". Essa última noção, particularmente utilizada naquela conjuntura, tornava-se igualmente fundamental na interpretação de Michel de Certeau, que caracterizava os eventos de maio como uma "ação simbólica que abre assim uma brecha em nossa concepção de sociedade" (1994e, p. 37). Como "brecha", forma de experiência que apenas

8 - Certeau tomava de Julien Freund (L'essence du politique) algumas de suas formulações sobre a representação política. 
podia se manifestar produzindo uma ausência no sistema de representação, as manifestações tornavam visíveis, inclusive, as discrepâncias entre a positividade da experiência vivida e o modo negativo (no sentido de recusa) de sua manifestação.

Nessa perspectiva, a retomada do poder, decorrida do desmantelamento das manifestações, podia ser comparada com formas anteriores de repressão às transgressões de grupos não dotados da palavra: "faremos de nossos concidadãos nossos índios do interior, por essa espécie de consumo que começa sempre por remover a fala de seus objetos?" (CERTEAU 1994b, p. 69). Como se pode notar, a transformação do outro, o indígena, em objeto de um saber, o apagamento de sua voz por uma etnografia que havia funcionado como uma máquina colonizadora do mundo ocidental, sua tendência a recuperar o estrangeiro apagando sua alteridade tornavam-se elementos de reflexão sobre a necessidade de uma decisão: "nossa sociedade julgará qual escolha será capaz de fazer" (CERTEAU 1994b, p. 69). Essa parecia uma questão central para Michel de Certeau: ao remeter ao problema da representação, mencionando suas dimensões relativas à política e ao saber, ele já havia indicado suas implicações teóricas (uma "escolha", uma "decisão"), tendo em vista, inclusive, que o caráter revelador do evento se relacionava com a forma nova de repensar a relação entre teoria e prática (em última instância, ela não recompunha fronteiras como aquela estabelecida entre o trabalho intelectual e o manual?).

A "decisão" teórica, por outro lado, não se descolava de seu componente cultural, pois o problema remetia para a forma com que uma sociedade lida com a alteridade, no caso, de um passado recente: como tratar daquele evento que, rapidamente, alcançou uma enorme bibliografia, além de muitas outras produções culturais (filmes, documentários etc.)? Política, cultural, a questão era ainda epistemológica: "na origem de uma ciência, há sempre opções éticas e culturais. Atualmente, os a priori históricos e sociais do nosso saber são mais claramente revelados como tais pelo acontecimento". E complementava: "Toda ciência humana deve introduzir a suspeita em seu 
próprio desenvolvimento (...). Ela está vinculada a uma forma de cultura. Para se definir novamente, deve fazer uma análise contestadora da civilização que ela postula" (CERTEAU 2012a, p. 172-173). Não bastassem essas dimensões, que tornam sua leitura multifacetada, poderíamos, finalmente, perguntar: não se poderia encontrar, na análise do evento, elementos que remetem sua interpretação também para o plano de uma ontologia efetivamente histórica ou mesmo para uma poética da temporalidade?

\section{O evento e sua temporalidade: implicaçōes para a historiografia}

Se o evento de maio-junho era um acontecimento "relevador", inclusive do ponto de vista epistemológico, sua interpretação era "uma tarefa uma vez política e teórica" (CERTEAU 1994d, p. 49; 1994c, p. 82). A reivindicação da relação entre essas dimensões era constante, já que a denegação do caráter inaugural do evento tinha consequências não apenas da ordem do saber, mas também ideológicas. Do ponto de vista do pesquisador, defendia Michel de Certeau, "a lei de seu pensamento não tem mais por função apenas proteger as leis de uma sociedade". Além disso, embora o historiador não pudesse desconsiderar experiências anteriores, "não é verdade que a novidade seja explicável pelos elementos já identificados, mas combinados diferentemente". Esse tipo de leitura criticada, redutora do princípio histórico do passado àquele da atualidade, restringiria a possibilidade de pensar a radical novidade daquela experiência, postulando "que nada pode se passar de outra forma em relação àquilo que já pensamos" (CERTEAU 1994d, p. 51, 53 e 54). E o problema era não apenas do historiador: "as ciências sociais estão condenadas a ignorar a novidade e a somente conhecer o homogêneo?" (CERTEAU 1994f, p. 110).

A antinomia entre evento e estrutura tampouco seria capaz de explicar a complexidade do ocorrido. Tema clássico das ciências sociais, ele foi colocado em pauta, sobretudo, no debate sobre uma suposta vitória da estrutura sobre o evento, 
compreendida como a retomada da palavra pelos órgãos governamentais (CERTEAU 1994b, p. 64-66). Para Michel de Certeau, "introduzindo o heterogêneo na homogeneidade da linguagem", o evento representava muito mais do que o contrário da estrutura, e o que estava em pauta, na realidade, era uma "tomada de posição em relação àquilo que escapa às regras de uma razão (social, científica, filosófica) como sua contestação 'incompreensível' ou inesperada" (1994c, p. 82-83). O evento, nesse caso, era a própria "diferença": "tanto na prática quanto na teoria, o diferente não é jamais o contrário. Recusamos ter, em teoria, que escolher entre a história e a estrutura; na prática, entre 'o movimento' de maio e 'a ordem' de junho. Na realidade, se trata de uma ordem diferente" (CERTEAU 1994b, p. 77). ${ }^{9}$ Atentar para a "diferença" seria uma atitude justamente contrária àquelas anteriormente apontadas, que, reduzindo o passado a uma estruturação ou reestruturação do já configurado (ou pensado), eliminavam a priori tudo aquilo que parecesse heterogêneo:

É necessário não somente constatar, mas admitir que nossos gestos e nossa história podem voltar com um sentido surpreendente para nós; que nossas próprias palavras podem dizer uma experiência não contrária (pois isto seria uma forma do Mesmo), mas diferente da nossa; que eles se tornam o instrumento de uma contestação, o vocabulário do outro (CERTEAU 1994d, p. 54-55). ${ }^{10}$

O que estava em jogo, de fato, era a abertura da possibilidade de pensar o evento e, portanto, o passado como diferença, como lugar da imprevisibilidade, do desafio às formas atuais do pensamento (o evento como "uma brecha em nossas formas de compreensão da sociedade"). Vale ressaltar que, embora essa forma de compreender o "evento" como "diferença" possa ser relacionada com a categoria différance, de Jacques Derrida, Michel de Certeau não utilizou, nos textos aqui citados, a noção com a mesma grafia do autor de Gramatologia (Derrida usava différance em distinção da palavra différence). Por outro lado, a categoria "diferença" foi utilizada por Certeau, em outros
9 - Sobre o "fato histórico" como "diferença", conferir, também, L'écriture de I'histoire (CERTEAU 1975a, p. 112-115).

\section{0 - Seria interessan- te uma confrontação entre a menção de Michel de Certeau às formas de retorno do passado com o diálo- go estabelecido por Paul Ricoeur com Hei- degger e Kierkegaard em torno da noção de "repetição" (RICOEUR 2007, p. 390-393).}


textos, em clara menção à leitura lacaniana sobre a forma de funcionamento do inconsciente, sobretudo no que diz respeito à figura metonímica do desejo como perpétuo deslocamento de uma diferença, por definição, nunca localizável. Sugestiva dessa relação também, é claro, é o uso da noção de "escritura" da história. Para além da implícita referência às escrituras sagradas, seu emprego poderia apontar uma escritura que se especializa por meio de traços, anteriormente à constituição dos binarismos associados a uma "metafísica da presença", o que remete novamente ao sentido conferido por Derrida à différance (binarismos como a própria antinomia entre evento e estrutura). ${ }^{11}$

Segundo Michel de Certeau, um texto não poderia existir sem implicar "uma posição doutrinal" sobre a "relação entre a teoria e a inovação, entre a linguagem e a violência". Assim, "é sem dúvida a função mesma da história (da historiografia) constituir, mais lucidamente, um discurso que enuncia uma relação da razão com o seu 'outro', com os eventos" (CERTEAU 1994c, p. 83). Como se pode notar, os acontecimentos de maio permitiam pensar algo constitutivo da historiografia como forma de lidar com o passado, uma condição inexorável que tornaria importante perceber os vínculos que o livro de história estabelece não apenas com o público visado, mas com os eventos futuros:

Sob a forma de um discurso que mantém uma relação com a heterogeneidade do passado, o livro contém, nele, o anúncio da relação que o autor pretende ter com aquilo que ainda permanece exterior e parcialmente imprevisível. Por exemplo, uma interpretação imperativa do passado é já intolerante em relação ao público ou aos eventos futuros. A literatura sobre maio pode ser analisada deste ponto de vista, como o teste de um saber ou o testemunho de uma sociedade sobre ela mesma (CERTEAU 1994c, p. 83).

A relação com o heterogêneo, com o público e com o futuro seria não apenas constitutiva da historiografia, mas definida como inscrita no texto ou no livro de história, ou seja, como configuradora da própria escrita: "esta relação [da historiografia com os eventos], interna ao texto, definia

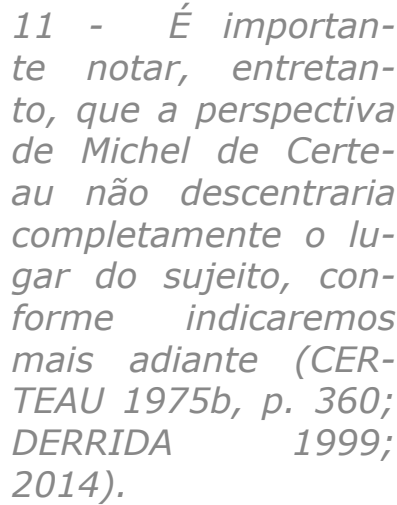

2014). 
assim sua posição [do historiador] sobre aquilo que the é externo, a saber, os leitores ou o futuro" (CERTEAU 1994c, p. 82-83).12 Tendo em vista a relevância conferida por Michel de Certeau à escrita como um dos componentes da "operação historiográfica" (1975a), certamente não é despropositado ressaltar o caráter fundamental dessa dimensão poética do trabalho do historiador, assim como a forma pela qual ela responderia a questões epistemológicas relacionando-as com preocupações ontológicas sobre o próprio estatuto do passado como "objeto" da historiografia. Conforme indicaremos mais adiante, essa chave de leitura, que aponta uma reflexão nas fronteiras entre uma ontologia e uma poética da temporalidade, pode ser aproximada daquilo que foi chamado de "ontologia da criação" por relação às obras de Cornelius Castoriadis (o conceito de "criação" foi desenvolvido por Castoriadis em textos posteriores, mas torna-se interessante perceber como elementos que serão fundamentais à sua reflexão estavam já presentes na interpretação sobre maio de 1968). ${ }^{13}$

A indicação dessas preocupações ontológicas, implícitas nos textos aqui analisados, não se torna forçada se considerarmos, inclusive, a crítica que Michel de Certeau formulava, no período, à forma como as análises científicas, de cunho histórico e sociológico, tendiam a excluir de seus discursos todas as suas pressuposições ontológicas. Em importante texto de 1971, no qual realizava essa crítica diretamente, sua reflexão girava exatamente sobre o papel do evento, sobretudo o evento como "ruptura instauradora", tal como Jesus Cristo, para os cristãos, remetendo implicitamente ao problema da temporalidade (o evento fundador do cristianismo, nesse caso, era confrontado com os cortes epistemológicos representados por Marx e Freud no campo científico). Sem dúvida, uma preocupação com as formas da escrita (uma poética) também atravessava esse e outros textos do período (CERTEAU 1987, p. 200 e 211-226). ${ }^{14}$

A noção de "criação", por outro lado, era ela mesma importante na caracterização do evento por Michel de Certeau: "uma experiência criadora, quer dizer, poética" (uma "multidão

\section{2 - Grifos meus.}

13 - Partindo de preocupações bastante diversas, Antoine Chollet (2015) também destacou esse aspecto da interpretação de Castoriadis e criticou a pouca frequentação pelos analistas de seus textos sobre 1968 (e de Lefort, pois realizou uma comparação entre ambos).

\section{4 - Uma interessante leitura sobre as preo- cupações epistemo- lógicas de Michel de Certeau foi realizada por Virgínia A. de Cas- tro Buarque (2004, p. 231-248).}


que se tornou poética") (CERTEAU 1994d, p. 42). ${ }^{15}$ A criação, nesse caso, poderia ser compreendida tanto do ponto de vista do caráter imaginativo da atividade historiadora, remetendo para um problema epistemológico (ou, poderíamos dizer, poético, considerando a escrita), quanto para o próprio estatuto ontológico do passado como experiência vivida. Na verdade, essas dimensões parecem inequivocamente vinculadas: o sentido conferido ao passado como experiência criadora era um problema "interno ao texto", conforme destacado, ou seja, parte do esforço poético. Considerar essa dimensão criativa, por fim, era ela mesma uma opção teórica e uma escolha política, como também já indicamos: era a relação do historiador com seu presente e com seu futuro, inclusive na figura da atenção ao significado do seu texto para o públicoleitor, que condicionava sua tendência a valorizar ou rejeitar a heterogeneidade do passado. Somente uma perspectiva atenta àquilo que o evento significava como o outro da razão, como alteridade, como "diferença" se mostraria aberta à percepção do caráter criador e inaugural da experiência de maio.

De certa forma, a reflexão de Michel de Certeau sobre os acontecimentos de maio-junho implicava uma caracterização daquilo que constitui o próprio "ser" do passado, seu estatuto como criação e, sobretudo, como temporalidade: o evento, uma "brecha", um corte político e epistemológico na lógica de uma sociedade e uma ciência enquadradas no tempo longo das estruturas, ao qual somente se podia contrapor uma noção de evento como ruptura, e não como diferença. A temporalidade do novo, da criação, do evento, por outro lado, não era um pressuposto incondicional, que conduziria a um determinismo na percepção da natureza ontológica daquilo que compreendemos como o passado. Isso porque a abertura à imprevisibilidade do passado tinha por consequência uma constante revisão dos próprios postulados do conhecimento, já que "o saber pode mudar com a experiência" (CERTEAU 1994b, p. 65).

Essa abertura para a radical novidade do passado, sem dúvida, se relaciona com a valorização do papel da 
historiografia e não foi por menos que Paul Ricoeur se voltou para as formulações de Michel de Certeau no diálogo crítico estabelecido com a obra máxima de Heidegger (RICOEUR 2007, p. 377-380). A valorização do evento, do passado como experiência criadora, além de poder ser relacionada com o vigor do "ter sido" que caracterizaria um nível mais autêntico de temporalidade na leitura heideggeriana, também não discrepava de uma atenção à dimensão epistemológica e política envolvida na "escolha" sobre como lidar com o passado. ${ }^{16}$ Por outro lado, era na abertura à imprevisibilidade e à heterogeneidade da experiência anteriormente vivida que radicava a condição de historicidade da própria historiografia, da constante revisão de seus pressupostos, sejam eles de natureza epistemológica ou ontológica. ${ }^{17}$

A indicada valorização da historiografia, cabe ressaltar, dependia justamente da sua capacidade de lidar com a diferença, inclusive naquilo que ela se expressava como forma de contestação do estatuto atual de um saber que, a partir da universidade, reproduzia o modo de organização hierárquico e massificado das instituições criticadas pelas manifestações de maio. ${ }^{18}$ Era preciso responder a essa situação na qual "'o outro' reaparece no coração da ciência como uma palavra que a contesta" (CERTEAU 1994c, p. 86). ${ }^{19}$ É nesse sentido que, aos condicionantes teóricos, epistemológicos e políticos da atividade do historiador, deveria ser acrescentado, com destaque, seu papel pedagógico, seja pela relação do livro de história com o público, conforme antes indicada, seja pela "homologia existente entre a atitude científica do professor diante dos fatos dos quais ele fala e seu comportamento diante dos estudantes aos quais se direciona". Ou seja, a atividade do historiador como professor era igualmente fundamental, sobretudo no caso das ciências humanas, nas quais "esta interferência entre o homem-objeto e o homem face-a-face" é ao mesmo tempo sua "grandeza" e seu "perigo". As vinculações entre o saber ensinado pelo cientista e a relação pedagógica teriam se tornado ainda mais claras devido às contestações, "graves e generalizadas", de maio, reveladoras da "relação
16 - Preferimos a leitura de A memória, a história, o esquecimento do que a de Tempo e Narrativa, pois esta reduz a obra de Certeau a uma sociologia da historiografia e a uma ontologia negativa do passado incapaz de alcançar o "ter sido" de experiências anteriores.

17 - O uso da versão primeira do texto de Certeau sobre a "operação historiográfica" (no caso, "operação histórica"), na qual a escrita não adquiria a devida relevância, talvez explique a intepretação limitada de Tempo e Narrativa (RICOEUR 2012, p. 253-266).

\section{8 - No texto "L'opéra-} tion historiographique", ao se perguntar acerca daquilo que o historiador "fabrica" e indicar com contundência a presença da cultura de massa na universidade, Michel de Certeau retomaria críticas semelhantes às realizadas em 1968 (1975a).

19 - Sobre o retorno do outro na linguagem científica e a forma como sua transformação em objeto afasta qualquer vestígio de alteridade, conferir também "La rupture instauratrice" (CERTEAU 1987, p. 204-209). 
teórica por meio da qual se fundava um conhecimento do homem, da sociedade ou do passado" (CERTEAU 1994c, p. 84).

A reflexão sobre a relação pedagógica, particularmente no ensino universitário, foi tema fundamental das manifestações de maio, fazendo parte de uma contestação mais ampla do próprio lugar do saber nas sociedades de capitalismo avançado. O teor burocrático e hierárquico das instituições acadêmicas contraditava com as justificativas do avanço científico, expressando a "incoerência" da relação entre a forma como um saber justificava seu estudo sobre os fatos humanos e as relações dentro da comunidade acadêmica. Ao invés de uma construção do saber como "interrogação mútua", entre professores e estudantes, ou mesmo entre os próprios estudantes, o que se podia encontrar eram "trocas definidas em termos de produções: objetos de pensamento, resultados de exames, cérebros ulteriormente utilizáveis". Nesse campo fechado das universidades, tornava-se surpreendente que a criação tivesse alcançado maior valor apenas no quadro de violência que condicionou as manifestações, o que tornava urgente redefinir as práticas pedagógicas, de modo a "permitir a cada um existir, ser diferente por sua relação com os outros, poder criar (e tornar-se outro ele mesmo) numa colaboração definida como um processo inventivo" (CERTEAU 1994c, p. 85).

Submetidas a uma lógica da produção, as práticas pedagógicas, na realidade, repercutiam as mesmas condições de "um saber identificado por um poder sobre os objetos", ou seja, submetido aos ditames relativos ao desenvolvimento de toda a civilização técnico-científica e o "tipo 'ocidental' de sociedade que ela criou" (CERTEAU 1994c, p. 86). Contestando essa forma de organização da sociedade em seu âmago, colocando em questão todo o seu sistema de representação, os movimentos de maio-junho teriam, então, legado ao presente a necessidade de uma revisão de postulados, inclusive no campo do saber, tornando necessária e urgente a realização de uma escolha. Uma escolha teórica, mas também política, que, em última instância, apontava a necessidade de uma revisão cultural 
mais ampla. ${ }^{20}$ Essa era, então, a leitura de Michel de Certeau, que intitulou um de seus textos de "Por uma nova cultura", indicando a necessidade de não negligenciar, marginalizando ou simplesmente colocando sob a manta do esquecimento, todo o teor criativo e inaugural das manifestações de maio. Esquecimento que, vale destacar, poderia ser produzido até mesmo pelo excesso de lembranças: bastaria confrontar o caráter coletivo e explosivo da experiência vivida com o estabelecimento de uma enorme bibliografia que somente podia ser "consumida" na calmaria de uma leitura silenciosa, bem distante dos ruídos das ruas (CERTEAU 1994f; 1994a).

\section{A "revoluçāo antecipada", segundo Cornelius Castoriadis}

O início das manifestações de 1968 estimularam a iniciativa de Cornelius Castoriadis de reunir novamente um pequeno grupo de intelectuais antes envolvidos com a publicação da revista Socialisme ou Barbarie, cujo último número tinha circulado em 1965. O grupo, por outro lado, havia deixado de existir desde o ano anterior, mas foi impulsionado a retomar as discussões devido aos acontecimentos, ainda que não tenha decidido voltar formalmente à existência. Nas reuniões, eles discutiam um texto produzido pelo próprio Castoriadis, inicialmente intitulado "Agir, réflechir, s'organizer", que logo passaria a circular nas universidades ocupadas pelos estudantes. Finalizado em maio de 1968, o texto aparecia, inicialmente, sob o pseudônimo de Jean-Marc Coudray, tendo em vista a avaliação de que, por ainda não ter adquirido nacionalidade francesa, Castoriadis corria risco de extradição pela atuação em favor das manifestações. ${ }^{21}$ No início do verão do mesmo ano, o texto já apareceria como integrante da publicação Mai 68: la brèche, sob o novo título "La révolution anticipée" e acrescido de uma segunda parte, centrada na originalidade da crise de maio de $1968 .^{22}$

Mai 68: la brèche contaria ainda com as análises de Edgar Morin, publicadas no mês de maio no jornal Le Monde, e com um texto de Claude Lefort, redigido em junho do mesmo ano.

\begin{abstract}
20 - A relação entre a escolha e a mudança de padrões culturais que permitam dar voz ao outro nem sempre foi clara em Certeau, como se pode verificar em texto de 1971 ,

no qual a dimensão da escolha não ganhou igual relevância explicativa (CERTEAU 1987, p. 209-226).
\end{abstract}

21 - Esses e outros pormenores da atuação de Castoriadis e sua relação com a Socialisme ou Barbarie foram examinados por Dosse (2018). No caso deste e de outros e-books, não indicaremos as páginas das citações, mencionando apenas tratar-se de livro digital.

\section{2 - A parte intitula- -se "L'originalité de la crise de Mai 68" e, embora tenha sido acrescentada como segundo item de "La révolution anticipée", a manteremos como referência separada nas citações, já que, ao leitor, pode inte- ressar o confronto en- tre os textos.}


Em linhas gerais, além das análises específicas de cada um desses intelectuais, pode-se perceber a retomada de aspectos centrais das interpretações produzidas durante o período de existência da Socialisme ou Barbarie, assim como leituras críticas às tentativas de enquadramento das manifestações em modelos preestabelecidos (sobretudo no que diz respeito àqueles que reproduziam as visões predominantes nas organizações partidárias com as quais ambos os autores se confrontavam desde, ao menos, os anos 1940). ${ }^{23}$ Posteriormente, por ocasião dos vinte anos das manifestações de maio, uma nova edição de Mai 68: la brèche foi publicada, juntamente com outras análises dos mesmos autores, que passavam a incidir também sobre as críticas mais recentes e sobre a memória do evento. Essa nova edição mantinha, é claro, o texto publicado já na versão de 1968, tornando-se matriz de reimpressões posteriores, tal como a que utilizamos em nossa análise. Ocasionalmente, faremos referência também a outros capítulos do livro, como o de Claude Lefort, pois sua confrontação permitirá aprofundar o estudo comparativo das leituras de Cornelius Castoriadis e Michel de Certeau. ${ }^{24}$

A interpretação de Castoriadis sobre maio de 1968 contém, de fato, elementos significativos que indicam relações com teses e preocupações desenvolvidas dentro de Socialisme ou Barbarie, com seu papel precursor na análise das singularidades dos movimentos contestatórios das sociedades burocráticas modernas (DOSSE 2018). Apesar de todo o acompanhamento realizado pelo grupo de várias manifestações anteriores, em países diversos, Castoriadis apostava na extrema novidade das manifestações de 1968, que colocavam em pauta não apenas um movimento contestatório, mas uma "afirmação" revolucionária radical em uma sociedade de capitalismo avançado. Questionava-se, no seu conjunto, os fundamentos da "civilização" moderna ocidental, com sua forma de vida baseada nas leis da técnica e do consumo, em modos de organização institucionais hierárquicos e burocratizados.

Além dos números expressivos, não apenas das movimentações estudantis iniciadas na universidade de Nanterre e difundidas pelo país, mas também dos milhões

\section{3 - Sobre a funda- ção do grupo Socia- lisme ou Barbarie, em 1946, e as discor- dâncias com o Partido Comunista Interna- cionalista e o Partido Comunista Francês, por exemplo, con- ferir as análises de Christophe Premat (2009b) e Antoine Chollet (2015).}

24 - Utilizamos uma edição mais recente (2008) da nova versão da publicação tal como existente desde 1988, que contém as reavaliações posteriores de Morin, Castoriadis e Lefort, intitulando-se Mai 68: la brèche suivi de Vingt ans après (MORIN et al 2008). 
de trabalhadores em greve por semanas, a novidade mais significativa dessa afirmação revolucionária se relacionava com o próprio âmago das contestações. ${ }^{25}$ Isso porque, longe dos modelos marxistas de revolução, centrados na contradição interna do capitalismo como conflito entre detentores dos meios de produção e classe produtora, o que estava em pauta era uma clivagem mais profunda das sociedades modernas, que separava dirigentes e executantes (conforme tese marcadamente presente em discussões anteriores da Socialisme ou Barbarie). Não por menos, os atores mais fundamentais da ação revolucionária seriam aqueles que a sociedade técnica colocava em "disponibilidade", definindo-os pela "irresponsabilidade" e os impulsionando para um confronto com a perda de sentido da vida moderna: os jovens, sobretudo os estudantes (CASTORIADIS $2008 a$, p. 177 e 188). A juventude não representava o único grupo social que contestava a ordem estabelecida, mas era, assim como uma intelligentsia envolvida com as estruturas da produção cultural, a principal veiculadora da "explosão criativa" das manifestações, "vomitando" o sistema atual e o futuro que ele impunha (CASTORIADIS 2008b, p. 129).

Nessa leitura, a universidade, com seu caráter "sacrossanto", era lugar de expressão dos valores arcaicos ainda existentes e da "crise mais profunda do saber e da ciência contemporânea". Colocando em questão esse sistema de modo mais amplo, buscava-se redefinir o próprio desenvolvimento do indivíduo, sua relação com a produção do conhecimento e com a autoridade, "pois o saber é a primeira sublimação do desejo do poder, de sua relação com a instituição naquilo que ela encarna como marco fixo e último" (CASTORIADIS 2008a, p. 191 e 192). Como se pode notar, tal como em Michel de Certeau e em outras análises do período, tratava-se de uma crise das instituições como formas de organização típicas das sociedades capitalistas modernas, entre as quais figurava a universidade como lugar de elaboração do saber numa perspectiva tecnicista, hierarquizada e produtivista. É nesse sentido que as noções de autogestão e auto-organização, colocadas em prática durante as ocupações universitárias, se tornavam fundamentais para

\section{5 - Em seu texto, es- crito entre 20 e 30 de maio de 1968, Cas- toriadis mencionou nove milhões de tra- balhadores em greve durante vinte dias. Posteriormente, Dos- se mencionaria dez milhões de grevistas parados por quase um mês (CASTORIA- DIS 2008b, p. 122; DOSSE 2018).}


repensar uma gestão autônoma e coletivizada, baseada na democracia direta como modo de organização da sociedade em perspectiva mais ampla.

Totalmente envolvido com essas expectativas, o texto de Castoriadis apresentava, inclusive, um conjunto de proposições em favor da difusão e consolidação dessa forma de organização. Na sua perspectiva, a revolução deveria adquirir um "rosto", os estudantes deveriam "fazer entender a sua palavra", realizar a difícil "transformação qualitativa" que permitiria a transição de um "movimento estudantil para um movimento global" (CASTORIADIS 2008b, p. 130 e 133). O desafio fundamental, nesse caso, era estabelecer formas de ação que não se confundissem com a construção de um "programa rígido e estereotipado", realizado por uma elite intelectual que se colocaria no lugar de único grupo reflexivo da sociedade. Essa tensão atravessa o texto de Castoriadis de modo geral e estava, segundo ele, no próprio âmago da contestação da sociedade moderna: era preciso repensar essas antinomias do sistema capitalista burocrático, ou seja, a divisão entre dirigentes e executantes ou entre aqueles que detêm ou não o saber.

Não se pode esquecer, nesse caso, que a antinomia entre ação e reflexão era também um problema central para Michel de Certeau. O questionamento de sua pertinência caracterizava não apenas sua análise dos eventos de maio, conforme destacado, mas fundamentou diversas de suas interrogações sobre a cultura, as quais permearam sua trajetória e estiveram na base de alguns de seus livros mais relevantes (particularmente, CERTEAU 2012b e 2009). A própria noção de "transgressão", anteriormente indicada, assim como suas interpretações sobre o caráter inventivo das formas de apropriação cultural, remetiam para os usos e reinvenções produzidos por aqueles que "não tinham um próprio", ou seja, tendiam a ser colocados no lugar dos não detentores do saber (ou, em outra formulação, desprovidos de uma linguagem própria, o que os restringia à possibilidade de promover deslocamentos e desvios na linguagem preexistente por meio de uma eventual "tomada da palavra"). 


\section{O estatuto ontológico do evento como criaçāo e a imprevisibilidade da história}

A antinomia entre ação e reflexão, que tornava um desafio estabelecer proposições para o movimento revolucionário, era apenas uma entre outras enraizadas nas formas de organização da sociedade capitalista burocrática, como, por exemplo, espontaneidade e organização, imaginação e racionalidade, reforma e revolução, festividade e seriedade. Neste caso, não bastava produzir uma síntese ou tentar ultrapassá-las, já que se tornava necessário destruir "o terreno mesmo no qual elas surgem incessantemente" (CASTORIADIS 2008b, p. 138). ${ }^{26}$ Tal como, na leitura de Michel de Certeau, não era suficiente tomar o evento como contraponto da estrutura, também Castoriadis não pressupunha uma simples negação ou inversão da lógica que caracterizava as formas atuais de organização social, indicando que, nesse caso, a via existente realmente era bastante estreita, inclusive no que diz respeito à relação entre teoria e prática, já que uma valorização da espontaneidade da ação não deveria inviabilizar a atitude reflexiva.

É justamente nesse ponto que a interpretação adquire mais densidade e relevância, mobilizando uma categoria que, futuramente, seria central em suas propostas em favor de uma "conversão ontológica radical" para repensar a sociedade e o imaginário (CASTORIADIS 1986, p. 232). Trata-se da noção de "criação", a qual permitiria considerar a imprevisibilidade das experiências humanas, assim como seu potencial na configuração de novas formas do social-histórico e dos modos de temporalidade que Ihes seriam correspondentes. A categoria, de fato, embora de forma ainda não problematizada, apareceu com recorrência nos textos sobre maio de 1968, seja para ressaltar o "imenso potencial criador da sociedade", a "explosão da atividade criadora dos jovens", as semanas de "criação intensa" então vivenciadas (CASTORIADIS 2008b, p. 124, 149 e 135), ou ainda, para contrapor a capacidade criadora da juventude à impossibilidade de criação do proletariado (muitas vezes, erroneamente compreendido como a única e verdadeira classe revolucionária)

26 - Em "Réforme et révolution dans l'université" (Le Monde, 9 a 12 de junho), Ricoeur buscou ultrapassar concepções revolucionárias e reformistas, distinguindo-se de Castoriadis por criticar o "mito da revolução" como evento global e único (DOSSE 2008, p. 398ss). 
(CASTORIADIS 2008a, p. 183). ${ }^{27} \mathrm{Na}$ realidade, era justamente a dificuldade imposta às novas formas de organização social de responder afirmativamente às antinomias do capitalismo burocrático que punha em primeiro plano a necessidade da criação. A reflexão teórica, embora fundamental, não bastava para tal, já que a invenção do novo deveria ser realizada igualmente enquanto prática, reconfigurando a contradição entre essas dimensões típicas da ideologia predominante:

Aqui ainda seria não somente ilusório, mas profundamente e principalmente falso querer responder por uma análise teórica à questão que a história põe à criatividade dos homens. Mas isto é certo: se existe uma solução para esse problema, ela não poderá ser encontrada fora da junção entre trabalhadores manuais e intelectuais. E se tal junção - que não é nada mais do que "natural" - deve ser realizada, ela somente poderá ser em função de um trabalho político-social permanente, cujas modalidades, estruturas, formas de ser estão por inventar quase inteiramente (CASTORIADIS 2008a, p. 194).

Escrevendo durante os acontecimentos, Castoriadis experimentava diretamente a imprevisibilidade que, na sua ótica, tornava um desafio "inventar quase inteiramente" essas novas formas do social-histórico. A essa demanda política e teórica, ele respondia ressaltando, por exemplo, o risco que as manifestações corriam de seu desmantelamento pela ação governamental, com sua consequente retomada das universidades. Mas, apostava também na necessidade de não "subestimar as imensas possibilidades que oferecerá o período histórico que se abre", enfatizando que, na história que "os homens estão criando, o sentido daquilo que se passa permanece largamente aberto" (CASTORIADIS 2008b, p. 171 e 121-122). Sua análise, neste caso, jamais pretenderia fixar o sentido do evento, mas permitir alguma orientação diante da imprevisibilidade, o que não o impedia de avaliar os resultados supostamente já alcançados: "passarão anos antes que a enorme brecha aberta no edifício do capitalismo burocrático seja verdadeiramente fechada supondo-se que ela possa ser" (CASTORIADIS 2008b, p. 172).
27 - Outras ocorrências da noção aparecem nas páginas $173,177,194$ e nas páginas 121-122 de "La révolution anticipée" (CASTORIADIS 2008b). 
A ideia do caráter permanentemente aberto do socialhistórico, assim como o uso da categoria "brecha", fartamente empregada no período, apareceriam em obras posteriores de Castoriadis. ${ }^{28}$ Analistas de outros textos ressaltaram também como, em sua proposta ontológica, seria inviável acreditar que somente possa existir no mundo aquilo que já teria sido pensado como possível, o que parece aproximá-lo do que foi anteriormente enfatizado sobre Michel de Certeau (PASTOR 2016). ${ }^{29}$ Por outro lado, uma concepção acerca da temporalidade parece igualmente implícita em suas interpretações das manifestações de maio de 1968, aproximando sua forma de entendimento do papel do evento daquilo que chamaria, em outros textos, de "imaginário radical". Nesse ponto, uma reflexão sobre o histórico e o ontológico, por via da temporalidade, pode novamente ser indicada, desta vez a partir dos textos de Castoriadis.

Com efeito, é interessante confrontar essa forma de compreensão da radical novidade das manifestações de maio com um dos elementos centrais da ontologia da criação de Castoriadis e sua centralização na noção de imaginário social. Tal esforço não visa, é claro, propor uma leitura anacrônica, projetando reflexões posteriores para textos de fins dos anos 1960, mas apenas sugerir a importância daqueles acontecimentos no desenvolvimento de suas ideias. Se Michel de Certeau interpretava o "evento" como o outro da razão, como alteridade, como "diferença", escritos posteriores de Castoriadis ressaltariam que "o tempo é o ser tanto quanto o ser é alteridade, criação e destruição" (CASTORIADIS 1987-1992, p. 286). A ideia do "tempo como criação e alteridade", nesse caso, se relacionava com aquilo que chamou de "imaginário radical" como uma das dimensões do social-histórico enquanto instituição imaginária.

Era por essa dimensão, de fato, que a temporalidade se manifestaria de forma mais plena e verdadeira, embora as significações sociais imaginárias comportassem também uma outra, chamada "conjuntista-identitária". Essa última se reduziria ao plano da determinação, da reconfiguração do preexistente, ao campo das possibilidades, ou seja, justamente
28 - Sobre a permanência do caráter aberto do social-histórico e a compreensão da história como um domínio no qual o sentido emerge, é criado, conferir Dosse (2018).

\section{9 - A crítica do en- tendimento da ver- dade como mera adequação e sua compreensão como a possibilidade de "abrir brechas no fechamen- to em que o pensa- mento sempre tende a se enclausurar no- vamente" aparecem em outros escritos de Castoriadis (1999, p. 294).}


àquela dimensão contrária à criação, ao surgimento do novo, na qual somente poderia passar a existir aquilo que já foi pensado (CASTORIADIS 1975 , p. 288)..$^{30}$ Se o social-histórico, enquanto instituição imaginária, se fundamentava na dialética entre essas duas dimensões, forçoso é perceber que existem claras similitudes entre a forma de caracterização do "imaginário radical" e das manifestações de maio como experiências nas quais o tempo é verdadeiramente criação, surgimento do novo, lugar efetivo de manifestação da própria história.

Essa compreensão da história como lugar de surgimento de uma alteridade radical, autêntica, absoluta constitui um elemento central em vários textos de Castoriadis, permitindo pensar a completa irredutibilidade das formas sociais e, portanto, como o contato com experiências outras do homem fundamentaria uma abertura do presente e do futuro, redefinindo e inserindo a contingência no próprio campo dos possíveis. ${ }^{31}$ Se é factível compreender suas interpretações sobre maio de 1968 como permeadas pela busca de experiências nas quais o elemento de criação torna-se fundamental, expressando uma outra temporalidade por meio do surgimento do novo em sua alteridade mais absoluta, cabe ressaltar o caráter coletivo dessa reconfiguração simbólica e imaginária das formas sociais. Da mesma forma, a abertura à heterogeneidade das figuras sóciohistóricas fomentaria uma predisposição para uma contínua redefinição dos parâmetros nos quais radicava sua leitura ontológica, sobretudo naquilo que diz respeito ao caráterúltimo da experiência histórica como plano da inovação e da alteridade. Sem dúvida, essa interpretação permite aproximar suas formulações da compreensão de Michel de Certeau sobre o evento como o outro da razão ou a própria diferença, igualmente inviabilizadora do aprisionamento em uma leitura determinista do caráter ontológico da história como experiência.

Essa chave de leitura, vale ressaltar, tende a afastar ambos os autores das tentativas de definição a-histórica daquilo que constitui o homem e a temporalidade. Na verdade, é interessante notar que nenhum dos dois deveria ser compreendido como
30 - Conferir, a esse respeito, as discordâncias entre Cornelius Castoriadis e Paul Ricoeur acerca do imaginário e seu potencial de criação/ reconfiguração (CASTORIADIS; RICOEUR 2005).

31 - A historicização da filosofia apareceria em vários textos: "Devemos retirar todas as ilações, particularmente do simples e reconhecido facto (...) que, por exemplo, a filosofia nasce na (e através da) sociedade e da história" (CASTORIADIS 2012, p. 128). 
exemplo de uma leitura promotora de um total descentramento do homem, apesar das diferenças que os caracterizam nesse ponto. Em ambos, notaremos um diálogo com a leitura lacaniana sobre a divisão constituinte como formadora do sujeito, afastando-os da segurança advinda da crença em um cogito autocentrado e autossuficiente, assim como permitindo valorizar o papel da linguagem como fundamento do imaginário. ${ }^{32}$ Por outro lado, a ênfase no potencial criador dos sujeitos históricos, se é evidente nas reflexões de Castoriadis, também estava pressuposta nos estudos certeaunianos das transgressões e das formas de apropriação cultural, conforme já destacado. A insistência maior de Castoriadis na criação como essência do homem, assim como a maior porosidade às consequências estruturais da leitura lacaniana como aparece em alguns textos de Michel de Certeau talvez revelem, por sua vez, nuances importantes. Maior porosidade, por fim, que não deveria conduzir à leitura de um Michel de Certeau totalmente lacaniano, que enredaria a escrita do historiador nos dilemas do discurso paranoico, conforme foi sugerido por Andrés Freijomil (2010). ${ }^{33}$

\section{Notas finais sobre algumas convergências e divergências}

As diferenças entre as perspectivas de Michel de Certeau e Cornelius Castoriadis, certamente mais bem compreendidas considerando obras posteriores, podem ser pensadas em relação às suas interpretações das manifestações de maio de 1968. Embora o primeiro também caracterizasse o evento como uma contestação do sistema de representação da sociedade em sua totalidade, conforme já indicado, sua leitura parecia mais próxima daquela de Claude Lefort, que utilizaria igualmente a expressão "revolução simbólica". Nessa perspectiva, tal como na "tomada da palavra" certeauniana, as ações de maio teriam tido uma "eficácia simbólica" justamente pela "brecha" aberta na sociedade, pela criação de um "novo espaço", um lugar de fala e de ação (um "não lugar"), um "possível indeterminado" que se modificaria de evento em evento (LEFORT 2008a, p. 62). ${ }^{34}$ Assim como na análise de Michel de
32 - O texto "La révolution anticipée" já continha uma reflexão sobre a relevância da imaginação, defendendo a ultrapassagem da dicotomia entre racionalidade e imaginário (CASTORIADIS 2008b, p. 138; 2012, p. 122ss; CERTEAU 1975a, p. $142 ; 1975$ c p. 381 382).

33 - É preciso considerar a diversidade de diálogos estabelecidos por Michel de Certeau, assim como a forma particular de sua apropriação das formulações de outros autores e, inclusive, as alterações que sofrem em seu pensamento ao longo do tempo.

34 - O texto de Lefort, elaborado especificamente para a coletânea Mai 68: la brèche, criticava contundentemente a forma de organização da universidade de então, assemelhando-se, neste caso, às críticas também formuladas por Certeau em La prise de parole. 
Certeau, esse tipo de compreensão não pressupunha que o sucesso do evento revolucionário dependesse de uma "tomada do poder" de fato, tal como era o caso em Castoriadis. Apesar de toda semelhança entre as leituras de Lefort e Castoriadis, indicadas tanto no vocabulário utilizado quanto nas teses sobre a radical novidade do evento ou no conflito central entre dirigentes e executantes, diferentes interpretações sobre o princípio de funcionamento do poder (ou mesmo do que seriam a "sociedade", a "política" e a "democracia") se traduziram em visões distintas sobre 1968 (CHOLLET 2015). ${ }^{35}$

Essas leituras particulares se refletiriam também nas reflexões posteriores sobre aqueles eventos, que procuravam se contrapor às interpretações críticas que se acumulavam acerca de supostos aspectos ou consequências negativas das manifestações, como o individualismo, o hedonismo ou o anti-humanismo que teriam se difundido a partir de então (CASTORIADIS 2008c; LEFORT 2008b; PREMAT 2009a). Não obstante, analistas atentos perceberam como, no próprio texto de 1968, seria possível encontrar elementos depois desenvolvidos em importantes trabalhos de Claude Lefort, quando suas concepções já estavam ainda mais claramente afastadas da perspectiva revolucionária de Castoriadis e a identificação, por esse último, da democracia direta como única verdadeira democracia (DOSSE 2018). É o caso das teses de Lefort sobre a democracia como experiência marcada pela imprevisibilidade e indeterminação, na qual o lugar do poder permaneceria "vazio", sem qualquer possibilidade de incorporação por um sujeito que the fosse consubstancial (LEFORT 1986 e 2011).

Em 1968, tomando as noções de "audácia" e "realismo" como representativas do estilo de ação de figuras conhecidas das manifestações, como Daniel Cohn-Bendit, Lefort tinha identificado o caráter inovador do movimento contestatório na recusa do mito de uma sociedade sem contradições, aproximando-se do modo como, posteriormente, conceituaria a democracia como "forma de sociedade" marcada por uma
35 - Em trabalho recente, examinei aspectos das formas de compreensão do poder de Lefort e Castoriadis, confrontando outras de suas obras com as de Paul Ricoeur e Marshall Sahlins por meio de um enfoque nos temas do imaginário e da historicidade (MARCELINO 2018). 
institucionalização do conflito, pelo seu caráter "trágico" e "selvagem". ${ }^{36}$ Essa leitura se distancia da proposta de tomada do poder e reinvenção total da sociedade de Castoriadis, expressando-se, nas análises posteriores, na diferença entre a ideia de uma "revolta de sucesso" (Lefort) e uma "revolução fracassada" (Castoriadis) (CHOLLET 2015, p. 52). O mais relevante, entretanto, é o quanto essas distintas interpretações estavam enraizadas em visões divergentes não apenas sobre as formas de organização da sociedade e sua relação com o poder, mas também em pressupostos ontológicos diferenciados sobre a imprevisibilidade da vida do homem como ser marcado pela "indeterminação" ou por seu potencial de "criação". Também nesse caso não se poderia deixar de ressaltar a presença da conceituação lacaniana do "real" nas obras de Lefort, com seus reflexos para pensar o próprio homem e a relevância dos planos do simbólico e do imaginário, o que aproximaria os três autores aqui mencionados. Pelos limites deste texto, entretanto, tornase pertinente manter a análise apenas sobre as concepções de Michel de Certeau e Cornelius Castoriadis.

Nesse plano, caberia não supervalorizar as semelhanças, sobretudo pelo modo como a radicalidade da crítica de Castoriadis acerca de qualquer pressuposto teológico, inclusive no que diz respeito às suas possíveis projeções na definição daquilo que configuraria o especificamente humano, o afastaria da leitura de Michel de Certeau. Em sua principal obra, publicada depois dos eventos de 1968, Castoriadis rejeitou de modo veemente a noção kantiana de "produção" para caracterizar a imaginação, relacionando-a com perspectivas posteriores, como as concepções "marxistas" e a ontologia heideggeriana, já que todas elas impediriam pensar a "criação" como verdadeiro fundamento do homem. Na raiz dessas perspectivas, Castoriadis identificava não apenas a compreensão do homem como ser finito, mas a pressuposição da infinitude de Deus, já que era na contraposição entre ambos que se fundamentaria essa "fantasia teológica" traduzida em "tese filosófica" (CASTORIADIS 1975, p. 275). Não é difícil perceber as diferenças entre esse manifesto ateísmo de
36 - Sobre a importância das noções de "trágico" e "selvagem" para pensar a democracia em Lefort, conferir a análise de Antoine Chollet (2015). 
Castoriadis e as fundamentações teológicas de muitas das reflexões de Michel de Certeau, expressas por sua atuação como jesuíta, mas embasando também questionamentos de textos dos mais diversos, como na figura do luto várias vezes utilizada para caracterizar a atividade historiográfica. ${ }^{37}$

Embora as experiências passadas tenham sido mais constantemente colocadas por Michel de Certeau no lugar desse objeto de luto, que tornaria a historiografia uma operação para lidar com a perda, não teria havido, em vários outros momentos, a sugestão de que o verdadeiro objeto dessa perda que se transformava em desejo era a própria infinitude de Deus? É certo que Certeau considerava essa perda com sentido divino, particularmente do corpo de Jesus Cristo, como condição de possibilidade do discurso cristão (a "ruptura instauradora"), estabelecendo, inclusive, confrontos com o discurso científico e seus "cortes epistemológicos". Por outro lado, seu constante diálogo com a obra de Emmanuel Levinas e sua interpretação mais geral sobre a relação entre a constituição dos domínios científicos e a crise de uma concepção de mundo centrada na figura de Deus, assim como a não hierarquização que fazia entre discurso religioso e historiográfico, parecem autorizar a relação estabelecida com o luto que fundamentaria a escrita da história (CERTEAU 1987, p. 187-226)..$^{38}$
37 - Sobre o luto que caracterizaria a "operação historiográfica", conferir a parte inicial de La falble mystique, sobretudo a página 15 (CERTEAU 1982; consultar também CERTEAU 1973).

38 - De Emmanuel Levinas, conferir, especialmente, Totalité et infini: essai sur l'extériorité (2001) e Dieu, la mort et le temps (1993).

\section{REFERÊNCIAS}

BUARQUE, Virgínia A. de Castro. A epistemologia "negativa" de Michel de Certeau. Trajetos, v. 5, n. 9/10, p. 231-248, 2004. Disponível em: http://repositorio.ufc.br/bitstream/ riufc/20382/1/2007_art_vacbuarque.pdf. Acesso em: 15 jul. 2018.

CASTORIADIS, Cornelius; RICOEUR, Paul. Paul Ricoeur e Cornelius Castoriadis. Diálogos sobre a história e o imaginário social. Lisboa: Edições 70, 2005. 
CASTORIADIS, Cornelius. Antropologia, filosofia e política. In: CASTORIADIS, Cornelius (Org.). A ascensão da insignificância. Lisboa: Editorial Bizâncio, 2012.

CASTORIADIS, Cornelius. Imaginação, imaginário, reflexão. In: CASTORIADIS, Cornelius (Org.). Feito e a ser feito. As encruzilhadas do labirinto - V. Rio de Janeiro: DP\&A Editoria, 1999. p. 241-295.

CASTORIADIS, Cornelius. L'imaginaire: la création dans le domaine social-historique. In: CASTORIADIS, Cornelius (Org.). Domaines de I'homme. Les carrefours du labyrinthe II. Paris: Seuil, 1986. p. 219-237.

CASTORIADIS, Cornelius. L'institution imaginaire de la société. Paris: Seuil, 1975.

CASTORIADIS, Cornelius. L'originalité de la crise de Mai 68. In: MORIN, Edgar et al (orgs.). Mai 68: la brèche suivi de Vingt ans après. Paris: Fayard, 2008a. p. 173-194.

CASTORIADIS, Cornelius. La révolution anticipée. In: MORIN, Edgar et al (orgs.). Mai 68: la brèche suivi de Vingt ans après. Paris: Fayard, 2008b. p. 119-172.

CASTORIADIS, Cornelius. Les mouvements des années soixante (1986). In: MORIN, Edgar et al (orgs.). Mai 68: la brèche suivi de Vingt ans après. Paris: Fayard, 2008c. p. 249-268.

CASTORIADIS, Cornelius. Tempo e criação. In: CASTORIADIS, Cornelius (Org.). As encruzilhadas do labirinto, III: o mundo fragmentado. São Paulo: Paz e Terra, 1987-1992. p. 261-294.

CERTEAU, Michel de. A estrutura social do saber. In: CERTEAU, Michel de (Org.). A cultura no plural. Campinas: Papirus, 2012a. p. 163-189.

CERTEAU, Michel de. A invenção do cotidiano: as artes de fazer. Petrópolis: Vozes, 2009. 
CERTEAU, Michel de. Ce que Freud fait de I'histoire. À propôs de "Une nevrose démoniaque au XVIIe siècle". In: CERTEAU, Michel de (Org.). L'écriture de l'histoire. Paris: Gallimard, 1975b. p. 339-364.

CERTEAU, Michel de. A cultura no plural. Campinas: Papirus, 2012b.

CERTEAU, Michel de. L'Absent de I'histoire. Paris: Maison Mame, 1973.

CERTEAU, Michel de. L'opération historiographique. In: CERTEAU, Michel de (Org.). L'écriture de I'histoire. Paris: Gallimard, 1975a. p. 77-142.

CERTEAU, Michel de. La rupture instauratrice. In: CERTEAU, Michel de (Org.). La faiblesse de croire. Paris: Seuil, 1987. p. $187-226$.

CERTEAU, Michel de. La falble mystique, 1: XI $\mathrm{XI}^{\mathrm{e}} \mathrm{XVII} \mathrm{e}^{\mathrm{e}}$ siècle. Paris: Gallimard, 1982.

CERTEAU, Michel de. La fiction de I'histoire. L'écriture de "Moïse et le monothéisme". In: CERTEAU, Michel de (Org.). L'écriture de l'histoire. Paris: Gallimard, 1975c. p. 365-419.

CERTEAU, Michel de. La moisson des éditeurs: mai vu de septembre. In: CERTEAU, Michel de (Org.). La prise de parole et autres écrits politiques. Paris: Seuil, 1994a. p. 88-105.

CERTEAU, Michel de. Le pouvoir de parler. In: CERTEAU, Michel de (Org.). La prise de parole et autres écrits politiques. Paris: Seuil, 1994b. p. 58-77.

CERTEAU, Michel de. Pour une nouvelle culture. In: CERTEAU, Michel de (Org.). La prise de parole et autres écrits politiques. Paris: Seuil, 1994c, p. 78-87. 
CERTEAU, Michel de. Prendre la parole. In: CERTEAU, Michel de (Org.). La prise de parole et autres écrits politiques. Paris: Seuil, 1994d. p. 40-57.

CERTEAU, Michel de. Une révolution symbolique. In: CERTEAU, Michel de (Org.). La prise de parole et autres écrits politiques. Paris: Seuil, 1994e. p. 29-39.

CERTEAU, Michel de. Une littérature inquiète: un an après. In: CERTEAU, Michel de (Org). La prise de parole et autres écrits politiques. Paris: Seuil, 1994f. p. 106-129.

CHOLLET, Antoine. Claude Lefort et Cornelius Castoriadis: regards croisés sur Mai 68. Politique et Sociétés, v. 34, n. 1, p. 37-60, 2015.

DERRIDA, Jacques. Gramatologia. São Paulo: Perspectiva, 1999.

DERRIDA, Jacques. A escritura e a diferença. São Paulo: Perspectiva, 2014.

DOSSE, François. Castoriadis, une vie. Paris: La Découverte, 2018.

DOSSE, François. Paul Ricoeur: les sens d'une vie (19132005). Paris: La Découverte, 2008.

DOSSE, François. Os engajamentos políticos de Gilles Deleuze. História: Questões \& Debates, Curitiba, n. 53, jul./dez., p. 151-170, 2010. Disponível em: https://revistas.ufpr.br/historia/ article/view/24120/16151. Acesso em: 15 dez. 2018.

FREIJOMIL, Andrés. Clío, entre Freud y Lacan. El gesto psicoanalítico en Michel de Certeau. Prohistoria, n. 14, primavera 2010. Disponível em: http://www.scielo.org.ar/scielo. php?script=sci_arttext\&pid=S1851-95042010000200004\&lng =es\&nrm=iso. Acesso em: 10 jan. 2019. 
GIARD, Luce. Par quoi demain déjà se donne à naître. In: CERTEAU, Michel de. La prise de parole et autres écrits politiques. Paris: Seuil, 1994. p. 7-26.

LEFORT, Claude. Essais sur le politique - XIXe-XXe siècles. Paris: Seuil, 1986.

LEFORT, Claude. A invenção democrática: os limites da dominação totalitária. Belo Horizonte: Autêntica, 2011.

LEFORT, Claude. Le désordre nouveau. In: MORIN, Edgar et al (orgs.). Mai 68: la brèche suivi de Vingt ans après. Paris: Fayard, 2008a. p. 43-81.

LEFORT, Claude. Relecture (1988). In: MORIN, Edgar et al (orgs.). Mai 68: la brèche suivi de Vingt ans après. Paris: Fayard, 2008b. p. 269-286.

LEVINAS, Emmanuel. Dieu, la mort et le temps. Paris: Grasset, 1993.

LEVINAS, Emmanuel. Totalité et infini: essai sur I'extériorité. Paris: Kluwer Academic, 2001.

MARCELINO, Douglas Attila. Estudos sobre poder, imaginação e historicidade dos anos 1970 e 1980: apontamentos para o debate atual. Tempo e Argumento, Florianópolis, v. 10, n. 24, abr./jun., p. 6-42, 2018. Disponível em: http://revistas.udesc.br/index.php/tempo/article/ view/2175180310242018006/8518. Acesso em: 15 jan. 2019.

MORIN, Edgar et al (orgs.). Mai 68: la brèche suivi de Vingt ans après. Paris: Fayard, 2008.

PASTOR, Jean Philippe. Castoriadis. La création des possibles. Paris: Moonstone, 2016.

PREMAT, Christophe. Mai 68, le conflit des interprétations. Sens Public, jun./dez., p. 1-11, 2009a. Disponível em: http://sens-public.org. Acesso em: 15 jan. 2019. 
PREMAT, Christophe. A la recherche de l'autonomie: le group 'Socialisme ou Barbarie' et Mai 68. Sens Public, jun./dez. 2009b. Disponível em: http://sens-public.org. Acesso em: 15 jan. 2019.

RICOEUR, Paul. A memória, a história, o esquecimento. Campinas: Unicamp, 2007.

RICOEUR, Paul. Tempo e narrativa III: o tempo narrado. São Paulo: Martins Fontes, 2012.

ZANCARINI-FOURNEL, Michelle. "La prise de parole": 1968, l'événement et l'écriture de I'histoire. In: DELACROIX, Christian et al (orgs). Michel de Certeau. Les chemins d'histoire. Paris: Complexe/IHTP, 2002. p. 77-86.

\section{AGRADECIMENTOS E INFORMAÇŌES}

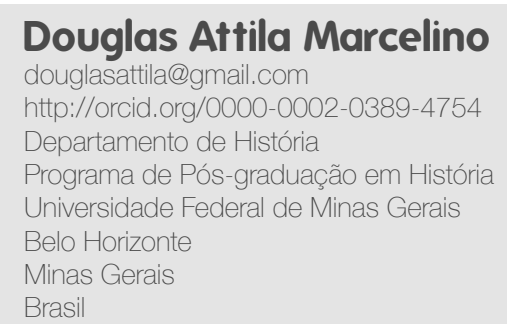

Pesquisa realizada com financiamento do CNPq. 